\title{
EL ARTE JONDO EN INTERPRETACIÓN ESTÉTICA DE LA ESTATUARIA MEGALÍTICA AMERICANA DE JORGE OTEIZA. LOS MOMENTOS CREADORES "SURREALES", "SUPERREALES" Y "PRECLÁSICOS" DE LA JUVENTUD CULTURAL: RESOLUCIÓN DE LA "PLÁSTICA PURA" O "VALORES ABSTRACTOS" EN LA ESTATUARIA JONDA DE SAN AGUSTIN
}

The art jondo in Interpretación estética de la estatuaria megalítica americana of Jorge Oteiza. The creative moments "surreal", "superreal" and "pre-classic" of cultural youth: resolution of the "pure plastic" or "abstract values" in the jondo statuary of St. Augustine

\author{
David Pavo Cuadrado \\ Universidad del País Vasco / EHU y Gobierno Vasco, España \\ davidpavocuadrado@gmail.com
}

Recibido: $28-02-2018$

Aprobado: 30-04-2018

\section{RESUMEN}

David Pavo Cuadrado es Jorge Oteiza utiliza en dos de sus libros, Interpretación estética de Licenciado en Bellas Artes en la la estatuaria megalítica americana (1952) y Goya mañana. El especialidad de Escultura, con un Máster en Investigación y Creación en Arte. Realiza un Doctorado inscrito en el Dpto. de Escultura de la Universidad del País VASCO / EHU, con ayuda Predoctoral del Gobierno Vasco. Es profesor del Dpto. Escultura UPV / EHU. realismo inmóvil. El Greco. Goya. Picasso (1946-1997), en un total de veinte ocasiones, la noción de "arte jondo": expresión singular del arte popular andaluz con la que se designa a los productos creadores más originales y alucinados en el ámbito del flamenco y la tauromaquia. Esta investigación particulariza en el uso que de ella hace en su interpretación estética en torno a las estatuas precolombinas de San Agustín en los Andes, Colombia. Oteiza se sirve del "arte jondo" en seis ocasiones para dar cuenta de un momento creador específico que abarca las etapas estilísticas consecutivas denominadas por él como "surrealismo", "superrealismo" y "preclasicismo". Su interés por lo jondo es inseparable de las nociones de "plástica pura" o "materia abstracta" que entiende imprescindibles para la determinación de todo resultado artístico, "Ser Estético" o "Estatua". La "estatuaria jonda", en tanto que invención, es un "Disparate creador" que garantiza "la originalidad absoluta" de toda cultura verdadera. Esta investigación se apoya en material inédito del archivo personal de Jorge Oteiza que contribuye a esclarecer y confirmar su interés por el arte jondo.

Palabras clave: Jorge Oteiza; estatuaria megalítica americana; arte jondo; plástica pura; Disparate creador 


\begin{abstract}
Jorge Oteiza uses in two of his books, Interpretación estética de la estatuaria megalítica americana (1952) and Goya mañana: El realismo inmóvil, El Greco, Goya, Picasso (1946-1997), in a total of twenty occasions, the notion of "jondo art": a unique expression of Andalusian folk art with which are named the most original and hallucinated creative products in the field of flamenco and bullfighting. This research goes into details of its use in his aesthetic interpretation of the pre-Columbian statues of San Agustín in the Andes, Colombia. Oteiza uses "jondo art" on six occasions to account for a specific creative moment that encompasses in the consecutive stylistic stages called by him as "surrealism", "superrealism" and "preclassicism". His interest in the jondo is inseparable from the notions of "pure plastic" or "abstract matter" that he understands essential for the determination of any artistic result, "Aesthetic Being" or "Statue". The "jondo statuary", as an invention, is a "Creator Nonsense [Disparate]" that guarantees "the absolute originality" of every true culture. This research is based on unpublished material from Jorge Oteiza's personal archive that helps to clarify and confirm his interest in jondo art.
\end{abstract}

Keywords: Jorge Oteiza; american megalithic statuary; jondo art; pure plastic; Creator Nosense [Disparate]

\title{
I.
}

En marzo de 1952, dentro la Colección Hombre e Ideas de la editorial madrileña Ediciones Cultura Hispánica, el escultor vasco Jorge Oteiza Embil (Orio, Guipúzcoa, 21 de octubre 1908 - San Sebastián, Guipúzcoa, 9 de abril de 2003) publica, con carácter de interpretación estética, una investigación en torno a la estatuaria precolombina de América, situada en el enclave geográfico de la cordillera de los Andes, en Colombia, en el entorno de San Agustín: Interpretación estética de la estatuaria megalítica americana (Oteiza, 1952; 2007; Muñoz, 2006) 1 .

Jorge Oteiza tiene conocimiento de esta cultura y de las estatuas de su expresión en fechas previas a su partida desde Bilbao a Buenos Aires en enero de 1935, a través de los estudios del arqueólogo Konrad Theodor Preuss (B: Preuss, 1931), al que se suman progresivamente los trabajos arqueológicos y geográficos de Francisco José de Caldas, Agustín Codazzi, Carlos Cuervo Márquez o José Pérez de Barradas (B: Pérez de Barradas, 1937; 1943). La resonancia primitivista de su escultura en esta etapa hace pensar en la influencia que pudo ejercer sobre ella esta estatuaria (Badiola, 2016, Vol. 1).

El sentido original del viaje a Latinoamérica retrotrae a la exposición que Jorge Oteiza, Nikolás Lekuona y Narkis Balenciaga realizan en los bajos del Kursaal de

\footnotetext{
${ }^{1}$ Atendiendo al material del archivo personal de Jorge Oteiza conservado en la Fundación Museo Jorge Oteiza (a partir de ahora FMJO) con el que se trabaja, el criterio que se sigue es: el indicado para referencias bibliográficas generales, precedido de $\mathrm{B}$ para volúmenes de su biblioteca personal, $\mathrm{D}$ para documentos de su archivo personal y $\mathrm{H}$ para su hemeroteca personal.
} 
San Sebastián en septiembre de 1934, planteándose una aventura por las culturas originales de distintos continentes: "las culturas Precolombinas" y "Perú, México, Persia y Egipto". Nikolás Lekuona no viaja y es asesinado en 1937 durante el conflicto bélico de la guerra civil en España. Narkis Balenciaga viaja pero muere en noviembre de 1935 en México. Jorge Oteiza es el único superviviente del movimiento que denomina Renacimiento vasco, satisfaciendo parcialmente el propósito original: la experiencia precolombina, visitando la estatuaria megalítica de San Agustín, y Perú (Oteiza, 1952, p. 13; 1988, pp. 5559; D: 1935).

En enero de 1935 viaja a Buenos Aires en el buque Arantza Mendi con Narkis Balenciaga (Oteiza, 1933; 1935a). Comienza un periplo vital y artístico de trece años, 1935-1948, decisivos en su carrera que le llevan a Argentina, Colombia, Ecuador, Perú o Chile (Pelay Orozco, 1979, pp. 311-324; Muñoa, 2006, pp. 6583). Experimenta uno de los períodos más efervescentes de su trayectoria, gestándose algunas de sus primeras investigaciones estéticas. Permanece activo en los movimientos culturales de las ciudades en las que vive. Continúa una práctica escultórica en la que, progresivamente, la incursión del espacio evoluciona paralela a una abstracción de herencia figurativa. La lectura y el estudio son una constante. Entre 1939 y 1941 forja un oficio estudiando química y técnica cerámica, siendo desde 1942 director de la Escuela de Cerámica de Bogotá. Publica artículos para la difusión de sus investigaciones (Oteiza, 1935a; 1935b; 1936; 1944; 1946a; 1946b; 1946c; 1947). Imparte conferencias, "hasta 20" en 1946, en Colombia, Ecuador o Perú (D: 1946a; 1946b; 1946c; 1946d; 1947). La aspiración a un "arte nuevo universal", cuya posibilidad reconoce inminente en América, preconiza sus intereses, propósito para el que la cultura precolonial de la estatuaria megalítica adquiere destacada relevancia. La etapa concluye con su vuelta a Bilbao en 1948.

Es en este contexto en el que se produce la investigación de Jorge Oteiza sobre la estatuaria megalítica americana. Va a tardar casi una década en contemplar en vivo y "abrazar" estas piedras: "hasta 1944 no llegué a tocar con mis manos algunas de las estatuas que buscaba". Para entonces, no sólo se había preocupado de las investigaciones realizadas por quienes le precedieron, sino que además, visitó y analizó algunos fragmentos líticos y cerámicos de esta cultura en los museos de la Universidad de Popayán, el Etnológico de Medellín, el de Rafael Larco Herrera en Trujillo o el de Chiclín, en Colombia y Perú: fragmentos antropológicos con los que complementa su estudio (Oteiza, 1952, pp. $15,47,83,102,132$ ). 


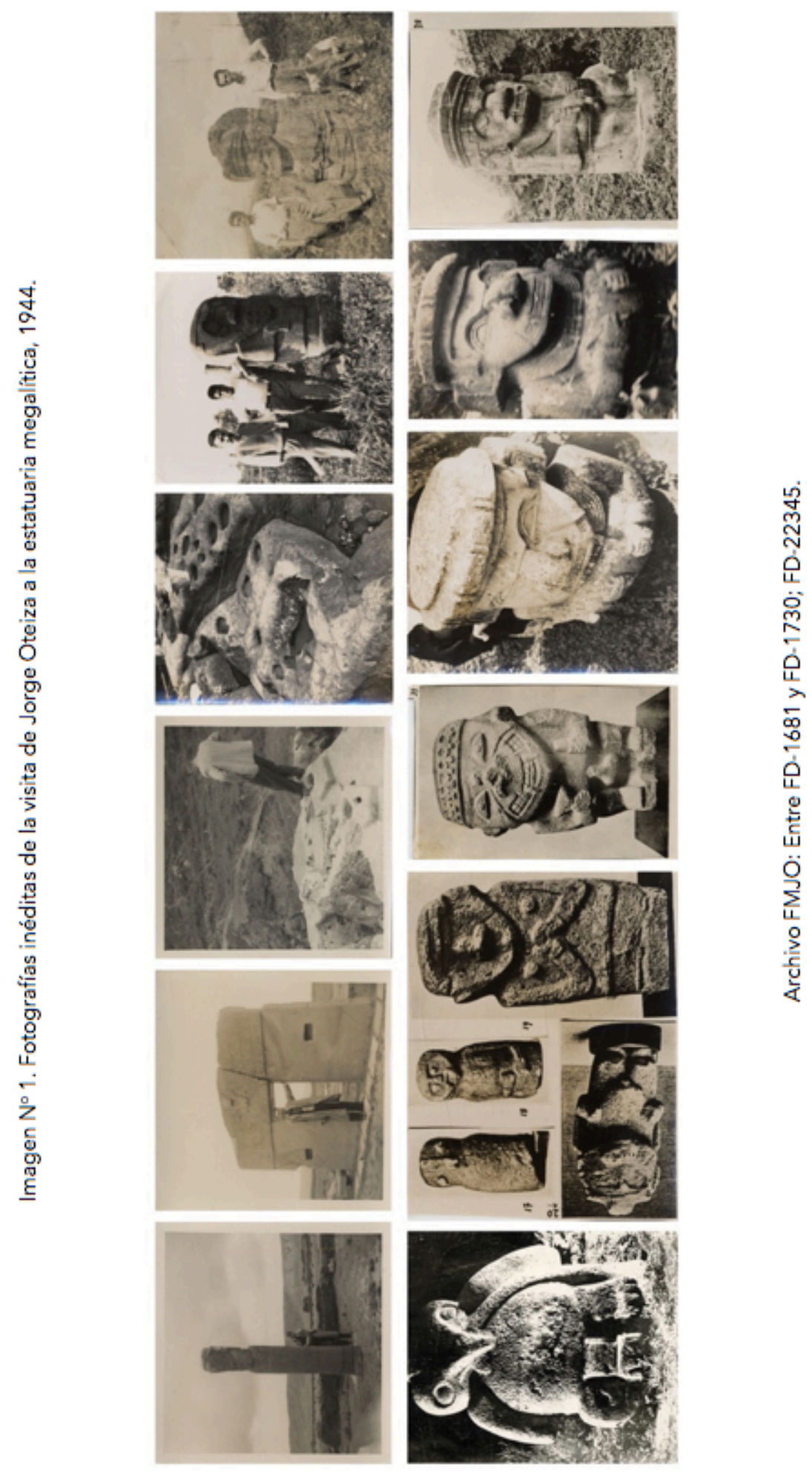


II.

\section{Trilogía sobre la expresión en arte (o El gran libro americano): arte nuevo universal americano, realismo inmóvil en el arte español y estatuaria megalítica de América}

En 1948 Jorge Oteiza regresa a Bilbao. Lleva consigo las conclusiones de sus estudios concentradas en un gran proyecto bibliográfico al que convenimos en denominar El gran libro americano y que agrupa bajo el extenso título El realismo inmóvil. Una estética objetiva con la interpretación estética de la estatuaria megalítica americana y la génesis europea de un arte mundial americano, fechado en 1948 (D: 1948). El proyecto concentra tres grandes temas que se van convirtiendo, progresivamente y a lo largo de 50 años, en libros individuales, no tanto independientes: como precedente, Carta a los artistas de América. Sobre el arte nuevo de la post-guerra (1944), y posteriormente, Interpretación estética de la estatuaria megalítica americana (1952) y Goya mañana. El Realismo inmóvil. El Greco. Goya. Picasso (1946-1997). Agrupados conforman una aproximación al proyecto original y una suerte de trilogía sobre la expresión en arte. En dos de ellos, Interpretación estética y Goya mañana, alude en un total de 20 ocasiones al "arte jondo".

\section{Jorge Oteiza y el arte jondo: panorama (flamenco y tauromaquia)}

Las referencias al arte jondo en su archivo personal y los casos biográficos que lo vinculan a artistas del flamenco y la tauromaquia, evidencian un interés en Jorge Oteiza por el arte jondo²: expresión singular con la que en el arte popular andaluz se alude a sus resultados más originales, alucinados y hondos. Para la investigación destacan dos conferencias que imparte, en 1946 en Bogotá, con motivo del bicentenario del nacimiento de Francisco de Goya y exposición de la serie de grabados La Tauromaquia (1816): Pintura de Goya y encuentro con el realismo metafísico del arte español, el 28 de marzo en la Casa de España, y Del estilo de Goya al realismo inmóvil, el 16 de abril en el Teatro Colón (D: 1946a; 1946b; 1946c; 1946d). Si se atiende a los mecanoscritos originales de estas

\footnotetext{
${ }^{2}$ Abordarlos excedería el propósito de la investigación. Algunos casos destacados, como su relación y colaboración con la bailaora Rosario Escudero, su interés en el torero Manuel Rodríguez 'Manolete' o el artículo Cante jondo de Gabriel Trillas de su hemeroteca personal, los traté en una conferencia con motivo de una exposición en homenaje al poeta y flamencólogo Félix Grande (1937-2014) titulada Jorge Oteiza y el arte jondo. Panorama y categoría estética: un estudio con referencias a Félix Grande impartida en el Museo Pérez Comendador-Leroux de Hervás (Cáceres, Extremadura, España) el 26.8.2017, repitiéndola el 11.12.2017 en la Facultad de Bellas Artes de la UPV/EHU.
} 
conferencias puede advertirse que en la primera se alude en cuatro ocasiones al "arte jondo", mientras que en la segunda el número de alusiones asciende a diez (D: 1946a, pp. 21, 23, 31; 1946b, pp. 49, 53), manteniéndose en la versión definitiva de estos textos publicados medio siglo más tarde en Goya mañana. Parece probable que la causa de este aumento sea el artículo Cante jondo de Gabriel Trillas publicado en el número de abril de 1946 de la Revista de América (H: Trillas, 1946), es decir, durante la veintena de días que separan ambas alocuciones y que anota profusamente. Mes y medio después de la segunda conferencia, en "Bogotá 8-mayo-1946" según la anotación manuscrita, Jorge Oteiza adquiere el libro El cante jondo. Origen y realidad folklórica de Clemente Cimorra (B: Cimorra, 1943), estudio flamencológico conservado en su biblioteca que corrobora su propensión a lo jondo. Con cronología paralela, Manuel Rodríguez 'Manolete' protagoniza una decena de artículos en su hemeroteca. Es en fechas justamente posteriores en las que redacta Interpretación estética de la estatuaria megalítica americana, pareciendo, artículo, libro e interés taurómaco, los principales motivos que detonan las alusiones al arte jondo.

\section{III.}

\section{El arte jondo en Interpretación estética de la estatuaria megalítica americana (1952)}

Jorge Oteiza alude en seis ocasiones al "arte jondo" en su ensayo sobre la estatuaría precolombina, con literalidad o mediante expresiones derivadas:

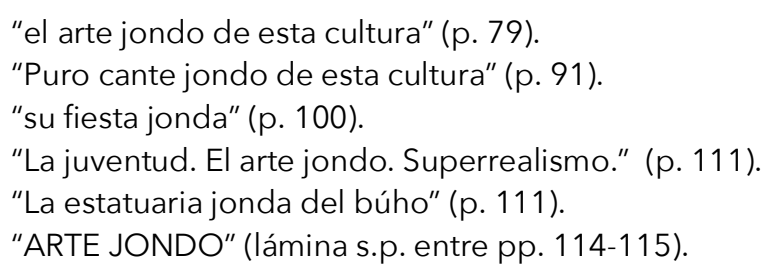

\subsection{Rostro y paisaje: la máscara (o la invención del mito)}

Al tratar en su investigación sobre la relevancia que adquiere el paisaje en la resolución de la obra de arte, Jorge Oteiza se sirve de la "máscara", construcción literal y al tiempo metáfora de artefacto de tipo estético, en la que se funden los rostros naturales y antropomorfos, diferenciándola de la "careta" o "antifaz", siendo la careta "reversible" y la máscara "irreversible". Considera necesaria una incursión en el paisaje y un regreso victorioso del mismo para su invención, 
mediante el "traslado estético de los factores cosmológicos del paisaje a la estatuaria": "elementos sagrados" con los que el creador se alía contra la muerte, mitificando al aliado y al enemigo, búho o jaguar y serpiente, respectivamente, en la megalítica. Jorge Oteiza se sirve de las palabras de Friedrich Nietzsche, "todo lo profundo necesita una máscara", para responder que "todo lo profundo es ya "máscara". Coincide, el tiempo de invención de la máscara, de "lo profundo", con el tiempo del arte jondo como regreso del paisaje: "Salida emocionante de la naturaleza. Puro cante jondo de esta cultura" (Oteiza, 1952, pp. 25-37, 91; D: s.f.-b).

\subsection{Ley de invención de lo abstracto: "plástica pura" o "valores abstractos"; y la incursión determinante de lo vital en el cálculo estético jondo}

Las cualidades plásticas y estéticas específicas del arte jondo pueden comprenderse mediante la herramienta para el desentrañamiento del "Ser Estético" o "Estatua", Ecuación Estética Molecular o simplemente Existencial, que Jorge Oteiza desarrolla por primera vez en esta investigación. Son tres los componentes o seres ontológicos necesarios para la obtención de un Ser Estético: SR, Seres Reales; SI, Seres Ideales; y SV, Seres Vitales. EI SR responde a las formas sensibles y temporales de la realidad natural: a la materia física del arte. El SI a las formas intemporales, matemáticas, que surgen de la imaginación: las formas geométricas fundamentales. Y el SV a las formas de lo sensible, sentimental, móvil, espontáneo: a lo que se siente momentáneamente. Jorge Oteiza señala que la primera materia a resolver en la Ecuación es la "materia abstracta" o "plástica pura", resultado de la colisión entre los dos primeros elementos (SR · SI), confrontación de la que resulta un ser plástico "binario" que entiende como "la más difícil obtención". Esta plástica "incompleta" se confronta en una segunda operación con el Ser Vital (SV), resultando en una aleación a la que denomina Ser Estético o Estatua, igualándolo a una X, como incógnita o enigma a descifrar. La "materia abstracta" o "plástica pura" de invención, que define el motivo del mito y material en el que se realiza, junto al sentimiento trágico, determinado por una necesidad de resolución urgente por la angustia existencial que singulariza este momento creador específico, van a dar cuenta de las cualidades de los productos estéticos jondos: "El arte jondo es el sentimiento trágico de los pueblos resuelto en expresiones certeras" y un grito plástico "arcaico" impostergable (Oteiza, 1952, pp. 49-63; 1997, p. 40). 
Imagen N². Ecuación Estética Molecular (Oteiza: 1984, p. 64).

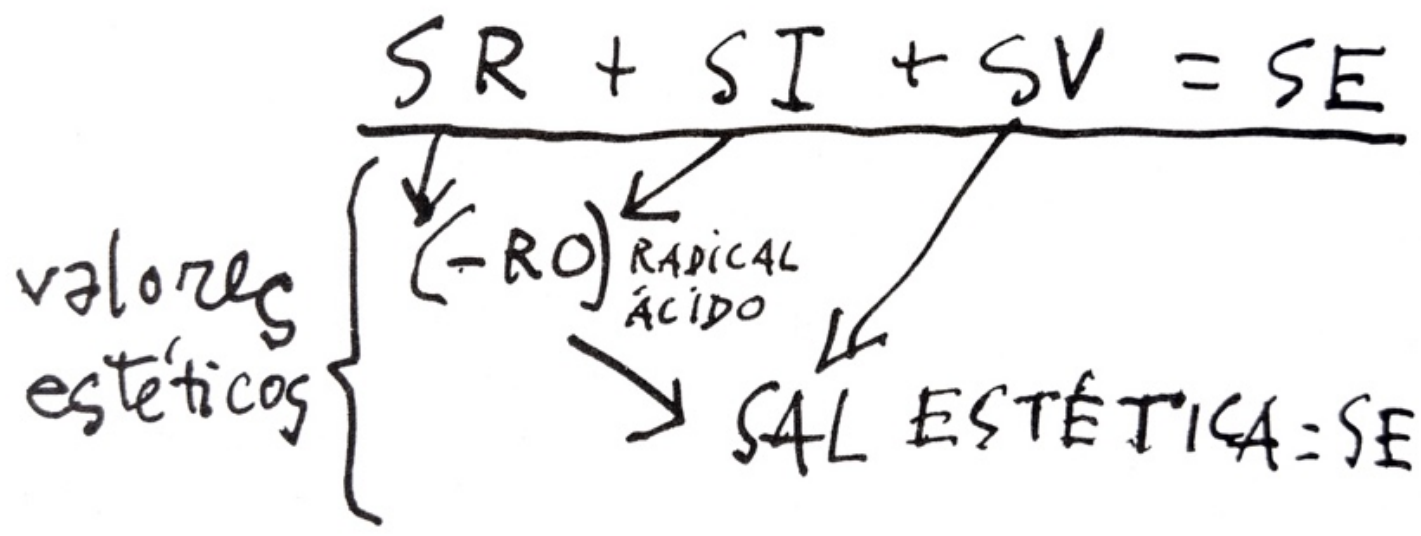

\subsection{Cómo se hace el Ser Estético jondo: el Disparate creador como afirmación estética}

Jorge Oteiza se sirve de la serie de grabados Los Disparates (1815-1824) de Francisco de Goya, para definir, oponiéndose a la idea de belleza, una noción con la que afirma que sin "Disparate creador" no hay salvación en arte:

"El SE es, pues, desde cada una de las naturalezas aisladamente, un disparate natural. El producto estético, en este sentido, es siempre un triple disparate. Contra el disparate de la muerte, el disparate de la creación eterna".

El "Disparate creador" es una "afirmación estética" en tanto que invención, en estilo superreal, donde sucede "una transformación química -estética- de las formas naturales" de modo "irreversible": "hay auténtico disparate creador, hay "caricatura" o máscara estética", y un resultado con "dimensión de lo perdurable". El Disparate es un producto meramente popular que Jorge Oteiza compara a los resultados más originales del cante jondo o la tauromaquia: El Disparate popular (el Arte Jondo), dice un epígrafe de su libro Goya mañana, atribuyéndole la doble cualidad de "realista" e "inmóvil" y ejemplificándolo con pinturas de El Greco, Goya, Picasso o una faena de Manolete (Oteiza, 1952, pp. 60-62; 1997, pp. 40-41). 


\subsection{Localización en la Ley de los cambios: tríada del "Surrealismo", "Superrealismo" y "Preclasicismo" (Adolescencia y Juventud cultural: el ARTE JONDO)}

Jorge Oteiza disecciona analíticamente en un cuadro sinóptico la cultura megalítica. Indica que es producida por 3 hombres o pueblos: A. San Andrés, B. Illumbe y C. San Agustín. Se desarrolla en 5 edades culturales: I. Niñez, II. Adolescencia, III. Juventud, IV. Madurez y V. Decadencia. Diferencia 5 estilos: Naturalismo, Surrealismo, Superrealismo, Clasicismo y Protobarroco. Y señala 7 momentos creadores: a., b., c. y d. (Naturalismo); e. (Surrealismo); f. (Superrealismo y Clasicismo); y g. (Protobarroco). En paralelo indica una etapa creadora: "ARTE JONDO".

Utilizando como cartografía su Ley de los cambios para los procesos artísticos, una herramienta de aspiración objetiva para la localización estilística, puede situarse el arte jondo en el devenir creador de una cultura. Esta Ley se desarrolla en dos fases complementarias e inversas: una primera convexa, de expresión, y una segunda cóncava, de impresión o vaciamiento de expresión. Estas dos fases se subdividen en estilos mediante los cuales la Ley se va completando progresivamente (Oteiza, 1957; 1963; 1984; 1990b). El arte jondo se produce en la etapa central de la fase expresiva durante los estilos consecutivos de "Surrealismo" y "Superrealismo": ambas denominaciones, aluden al carácter realista, con los prefijos sub- y súper-, lo desordenado y lo sobresaliente respectivamente, al tiempo que se engloban en lo pre- de la etapa que les sigue, el "Clasicismo".

El surrealismo es un "Naturalismo donde las formas individuales" sufren una "alteración del orden espacial" cuando "el artista experimenta incruentamente con la naturaleza". En el superrealismo "se efectúa la dislocación formal" y se "quebranta el rostro individual de las cosas, haciéndose imposible su regreso al estado natural anterior". Y el preclasicismo es un tiempo de transición del superrealismo al clasicismo. 
El "ARTE JONDO" se produce entre las edades de adolescencia y juventud, por los pueblos de Illumbe y San Agustín, en estilo surreal y superreal, durante los momentos creadores d. y e.:

III. El hombre de San Agustín: La juventud. El arte jondo: superrealismo. El descubridor de la fe. El del gran sentimiento trágico. El hombre-jaguar.

d) La estatuaria jonda del búho. Surrealismo preclásico, ascendente. (...) casi alcanza a fundirse con el búho. Garantía absoluta de la originalidad de esta cultura del hombre-jaguar. Escultor trágico (nace la iglesia).

e) Superrealismo. -Contacto en la estatua, del hombre con el jaguar. (...) Evolución estética de la plástica redonda a la cúbica y entrada en las grandes cabezas. (Oteiza, 1952, pp. 61-62, 109-115).

\subsection{Estatuaria megalítica jonda: del búho con serpiente de plástica redonda de Illumbe al escultor-jaguar de San Agustín, y los guerreros "moneadores" (lidiadores de monos) de la Fiesta nacional}

Tras los tanteos naturalistas, las estatuas comprendidas de la 16 a la 24, situadas en las edades II y III (Adolescencia y Juventud), conforman el grupo de la "estatuaría jonda" megalítica. El conjunto se subdivide en dos grupos: el primero reúne las piedras relativas a la representación del búho con serpiente en el pico halladas en el Alto de la Huacas y Alto de La Pelota, en el contexto de Illumbe. Es el hombre de lllumbe, en resultados líticos surreales y superreales consecutivos, el escultor jondo de los mayores tanteos y vacilaciones a favor de una posible alianza con el búho que finalmente abandona. El segundo, en la meseta de San Agustín, avanzando en productos superreales e intentos de alianza con el jaguar, obtiene las primeras fusiones de rostros, y con ellas, un preclasicismo, que es al mismo tiempo una decadencia del arte jondo. 

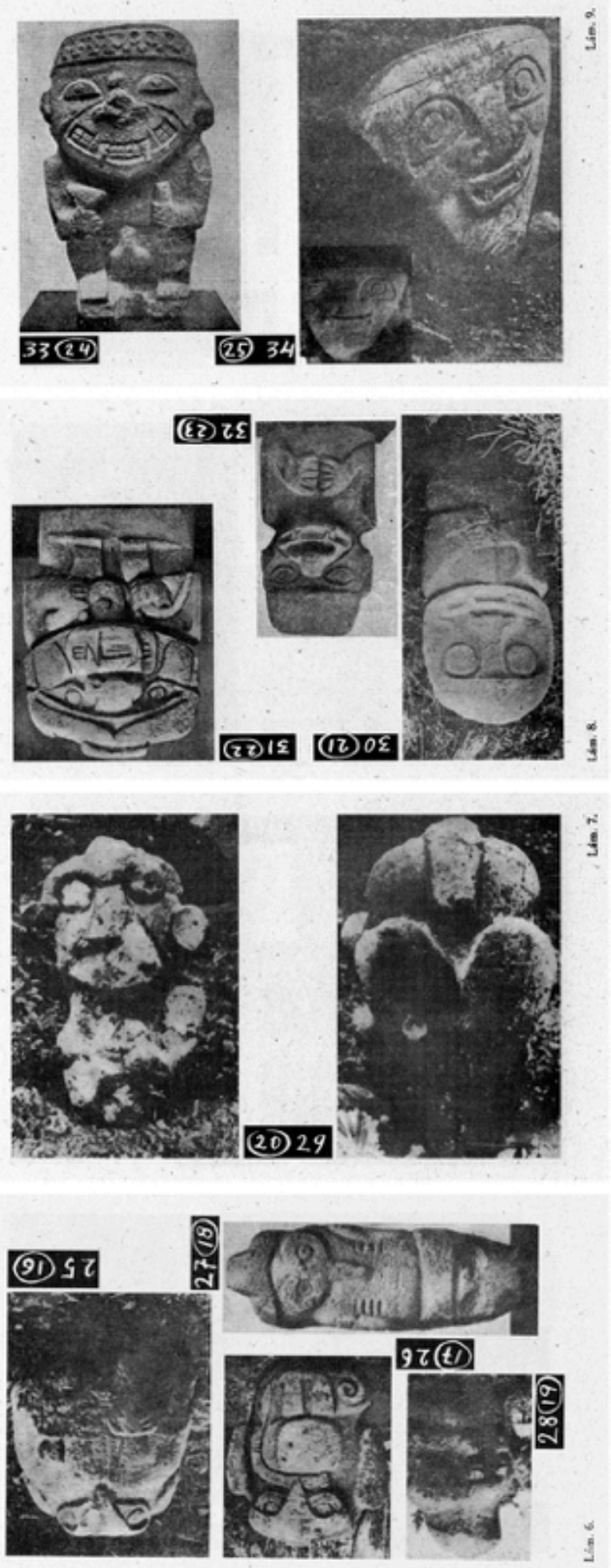


\section{$1^{\mathrm{a}} .25$ (16)}

Esta piedra tiene un precedente en la estatua de estilo naturalista 22 (12): "la voluntad artística multiplica la imagen del búho con una serpiente en la boca o con dos cabezas de serpiente, como cetros en las garras". Le siguen otros tres precedentes, las estatuas 13, 14 y 15: "Tres piedras con la representación humana de una cabeza, un busto y una figura completa" en "estilo primitivo de la talla bajo antecedentes ceramistas" -afirma refiriéndose a las cerámicas de San Andrés-, porque "Obedecen estas representaciones a modelos efectuados sobre el barro". De la estatua 16 sólo comenta que es "Búho con serpiente (de plástica redonda)". Comienza en ella el tiempo del arte surreal y jondo. Su forma oval hace que su peso plástico se sitúe en la parte inferior, dando sensación de gravidez: "El animal con garras, el búho con la serpiente, corresponde a la plástica inicial redonda. Luego hay un avance formal notable: plástica cúbica".

\section{$2^{a} .26(17)$}

Es la segunda piedra surreal y jonda de lllumbe: "Búho con serpiente (plástica cúbica)". Insiste esta estatua en la misma representación, pero centralizando su peso, aproximándose a la forma del cubo. Dice Jorge Oteiza sobre la "plástica cuboide" que es "lo redondo ascendente" y la plástica cúbica" la "Inteligencia de lo monumental como inversión de la pirámide" que permite la "ascensión del peso plástico de una estatua": motivo por el cual tienen estas piedras "una impresionante actualidad".

\section{$3^{\mathrm{a}} .27$ (18)}

También de "plástica cúbica", esta estatua, es un intento de mímesis con el animal para convertirse en "hombre-búho" mediante el disfraz, combinando elementos antropomorfos y zoomorfos. Es el momento plástico central del surrealismo, un ejemplo de disparate en tanto que invención milagrosa, "afirmación estética de (...) los grandes Disparates": "la historia del hombre se mueve por milagros. Cada milagro es un pensamiento original. No hay invención sin disparate". 


\section{$4^{\mathrm{a}} .28(19)$}

Su descripción dice: "Hombre con máscara de búho con dos cabezas de serpiente en las manos". Es una gran roca con forma pseudo-antropomorfa. Su peso plástico asciende situándose en torno al pecho. Es uno de los productos en arte jondo más emocionantes de esta lítica y uno de los grandes Disparates surreales de lllumbe, alcanzado con ella el arte jondo la cumbre de su manifestación:

Salida emocionante de la naturaleza. Puro cante jondo de esta cultura. La prueba de la originalidad de esta estatuaria - de esta mitología- es esta constante -en este periodo de lllumbe- y terrible indecisión por fijar la solución definitiva de su aliado contra la serpiente. Vale decir, la decisión heroica por resolver la forma mental -el cálculo estético- de su angustia existencial, su comunión con Dios.

Tipo popular de la intuición creadora, tan grande como la que más tarde va a fijar la alianza del hombre con el jaguar.

\section{$5^{a} .29(20)$}

Supremo Disparate precolombino y gran estatua-siguiriya o grito lítico, en conmovedor ayeo de la forma, y el momento creador más emocionante de esta estatuaria como pura manifestación en arte jondo, donde los elementos zoomorfos sagrados del paisaje comienzan una fisión estética irreversible: "Es el "hombre-ángel"', resultado de una invención plástica en heroísmo decisivo propiciado por la angustia que mantiene a este escultor en una pulsión de muerte. La describe como "Hombre-búho (parte anterior): hombre-ángel, la misma (parte posterior)". Comenta sirviéndose de la poesía de San Juan de la Cruz y Walt Whitman que es "Máquina de vida eterna, "llama de amor viva"'" y alude a su "propósito oculto":

Una de las piedras más extraordinarias de cualquier estatuaria. Intuición plástica tan formidable como la que en la tradición cristiana da lugar a la aparición del ángel.

Sobre ella destaca una afirmación que entronca directamente con los productos marginales -impopulares- del arte jondo:

De aquí podría haber arrancado toda una cultura lítica distinta a la que se dio en San Agustín. Probablemente no alcanzó la popularidad necesaria, o su proyección posterior política no fue suficiente. 


\section{$6^{\mathrm{a}} .30(21)$}

La primera piedra del segundo grupo de estatuas jondas, en estilo superreal, representa a una persona oculta tras una máscara de jaguar. Es una nueva intuición y tentativa de fusión de rostros, emplazando al búho para iniciar un intento de alianza que va a ser definitiva con el jaguar, aproximándose a un preclasicismo con el que el arte jondo, como invención mítica salvadora, entra en declive progresivo.

\section{$7^{\mathrm{a}} .31(22)$}

Este "hombre-jaguar" se representa dominando a la serpiente: "Aparece así como más jaguar y menos hombre", como salvación mítica -"el cristo"-, declinándose hacia un "equilibrio clásico": "los métodos de salvación no se transmiten; quien no crea su propio arte -sin arte original- no sobrevive". Es puro Disparate creador.

\section{$8^{\mathrm{a}} .32(23)$}

Esta estatua es "Expresión superreal, irreversible. Fusión "química" perfecta de los rostros aliados contra la serpiente" en alianza definitiva del hombre con el jaguar: "la sustancia divina ha sido hallada", dice Jorge Oteiza. Es el tiempo de los productos preclásicos, momento de transición entre el superrealismo, o el arte jondo -dinámica o inestabilidad-, y el clasicismo -estabilidad-.

\section{$9^{\mathrm{a}} .33(24)$}

Es la última estatua perteneciente a la etapa creadora del arte jondo. El escultor agustiniano se representa a sí mismo, con cincel y martillo, colmillos y ojos felinos, y el falo erecto, orgulloso del logro estético de su alianza con el jaguar: "culminación del superrealismo inferior arcaico, preclásico. El escultor victorioso". El arte jondo culmina con esta piedra: "La cultura agustiniana había sido ya conquistada". 


\title{
$10^{\mathrm{a}} .42(28)$
}

Esta pareja de estatuas no pertenece al tiempo del arte jondo, sino al final de un clasicismo avanzado que se aproxima a un "protobarroco". Jorge Oteiza las comprende como representaciones del juego, deporte o fiesta del pueblo, describiéndolos como "Guerreros. Gladiadores agustinianos. ¿Zoómacos?" que compara al torero:

Tuvo este pueblo, sin duda, una fiesta nacional, como los gladiadores en Roma, los toros en Creta y, más aproximadamente, como la suerte de los toros en España.

Este taurómaco precolombino lidia al mono, que lleva en el tocado: "es el cazador, el zoómaco, el moneador que lidiaba al mono (?) (...) -monomaquia-". En la mano derecha tiene una piedra para "azuzar y provocar el ataque del animal: constituye lo que la muleta o el engaño en la lidia del toro" y en la izquierda una lanza para "atacar mortalmente a su enemigo": "Esto debió ser el espectáculo popular agustiniano, su fiesta jonda, lo que la tauromaquia al pueblo español" (Oteiza, 1952 pp. 89-100, Lámina 6, 7, 8, 9 y 13 s.p.).

\section{IV.}

\section{ARTE JONDO: garantía de originalidad y una categoría estética}

Jorge Oteiza advierte en su interpretación estética de la megalítica americana:

\begin{abstract}
vacilaciones (...) de una plástica ascendente, que alcanza, en momentos que señalaremos, un encanto espiritual, poéticamente rudo, popular e incomparable. Son precisamente los momentos que luego, en alguna nota ampliadora, designaremos como el arte jondo de esta cultura.
\end{abstract}

Sin más precisión sobre el sentido de este elemento, a priori, extraño en su investigación, lanza al lector a un encuentro con el "cante jondo" precolombino, la "estatuaria jonda" del búho o la "fiesta jonda" nacional.

Lo que Jorge Oteiza señala como "ARTE JONDO" es un producto de cualidades plásticas y estéticas específicas, correspondiente a un momento creador ineludible en la evolución de toda cultura, y con ello, una categoría estética para la teoría del arte en su interés por una Estética Objetiva. El arte jondo es la expresión certera y popular, sagrada y humilde, de los pueblos, al resolverse con su angustia y en comunión con el paisaje, definiendo su cosmogonía en la 
estatua, como Disparate que se afirma a sí mismo estéticamente, y en ella, un mito de invención que concreta su "materia abstracta" y sentir existencial. En la megalítica americana, y en extensión, en toda cultura, el arte jondo es para Jorge Oteiza prueba y garantía de originalidad: "Puro cante jondo de esta cultura. La prueba de la originalidad de esta estatuaria - de esta mitología-"; "La estatuaria jonda del búho (...) Garantía absoluta de la originalidad de esta cultura"; "precisión ejemplar y austeridad y laconismo espiritual. Una proeza (...) prueba evidente de su originalidad y su verdadera riqueza estética". El "arte jondo" como noción estética, le brinda la posibilidad de dar cuenta, metafóricamente, de una estatua específica que, como cante jondo y toreo jondo -en tanto que equivalente plástico y estético, existencial y creador- erigido en piedra, entronca con un grito original que siente propio: "el vasco se ha convertido en andaluz: dejó en el aire su grito jondo", anota en el artículo Cante jondo, o relaciona a su vuelta al País Vasco el "JONDO" con el vacío de la estatuaria original de su pueblo, el "CROMLECH" microlítico pirenaico. Su estancia en América, la posguerra española, y especialmente, su propia angustia existencial en este momento vital, condicionan decisivamente su interés por el arte jondo y su incursión, verdaderamente calculada, en Interpretación estética de la estatuaria megalítica americana. (Oteiza, 1952, pp. 91, 111, 120; 1990a, pp. 46-47; 1995; 1996; D: 1981; s.f.-a; s.f.-c; H: Trillas, p. 237). 


\section{BIBLIOGRAFÍA}

\section{BIBLIOGRAFÍA GENERAL}

Badiola, Txomin. (2016). Oteiza. Catálogo razonado de escultura. Alzuza: FMJO.

Muñoa, Pilar. (2006). Oteiza. La vida como experimento. Irún: Alberdania.

Muñoz, Ma Teresa. (ed.). (2006). Las piedras de San Agustín. Sobre la estatuaria megalítica de Jorge Oteiza. AA.VV. Madrid: Mairea Libros.

Oteiza, Jorge. (1933). "Exaltación de la caverna. La cueva de Altamira y la cueva de Arrona. El pintor Balenciaga". El Pueblo Vasco. San Sebastián, 5 de febrero. p. 5 .

- (1935a). "Un pintor del Renacimiento Vasco" [Narkis Balenciaga]. Iberia. Bahía Blanca, Argentina, 14 de abril. p. 24.

- (1935b). "De la escultura actual de Europa. El escultor español Alberto Sánchez". Arquitectura. № 1. Santiago de Chile, agosto. pp. 6-7.

- (1936). "Defiendo mi obra de arte contra todas las fronteras del fascismo". Literatura, arte cinema. Chile: 27 de octubre.

- (1944). Carta a los artistas de América. Sobre el arte nuevo en la post-guerra. Separata de la Revista de la Universidad del Cauca, n 5. Popayán, diciembre. pp. 75-109.

- (1946a). "La estatua en Colombia. El nuevo escultor Edgar Negret". Revista de América, n 13. Bogotá, enero. pp. 93-98.

- (1946b). "Descubrimiento de Ráquira". Revista de las Indias, n 86. Bogotá, febrero. pp. 237-250.

- (1946c). "El recuerdo. Grandeza y miseria de Zuloaga". Revista de América, n 15. Bogotá, marzo. pp. 402-407.

- (1947). "Del escultor español Jorge Oteiza. Por él mismo". Cabalgata. № 2. Buenos Aires. pp. 6-7. 
- (1952). Interpretación estética de la estatuaria megalítica americana. Madrid: Ediciones Cultura Hispánica.

- (1957). Propósito experimental. IV Bienal de São Paulo, 1957. Catálogo autoeditado.

- (1963). Quousque tándem...! San Sebastián: Auñamendi.

- (1984). Ejercicios espirituales en un túnel. San Sebastián: Hordago.

- (1988). Cartas al príncipe. Zarauz: Itxaropena.

- (1990a). Existe Dios al Noroeste. Pamplona: Pamiela.

- (1990b). Ley de los cambios. Zarauz: Tristán-Deche.

- (1995). Estética del huevo. Pamiela.

- (1996). Nociones para una filología vasca de nuestro preindoeuropeo. Pamplona: Pamiela.

- (1997). Goya mañana. El realismo inmóvil. El Greco. Goya. Picasso. Alzuza: Pamiela; FMJO.

- (2007). Interpretación estética de la estatuaria megalítica americana / Carta a los artistas de América. Sobre el arte nuevo en la post-guerra. Edición crítica, facsímil y bilingüe a cargo de $M^{a}$ Teresa Muñoz. Alzuza: FMJO.

Pelay Orozco, Miguel. (1979). Oteiza. Su vida, su obra, su pensamiento, su palabra. Bilbao: La Gran Enciclopedia Vasca.

\section{BIBLIOTECA DE JORGE OTEIZA EN FMJO}

Cimorra, Clemente. (1943). El cante jondo. Origen y realidad folklórica. Buenos Aires: Shapire. FB-198.

Pérez de Barradas, José. (1937). Arqueología y antropología precolombinas de Tierra Dentro. Bogotá: Ministerio de Educación. FB-3244. 
- (1943). Arqueología agustiniana: yacimientos y monumentos. Bogotá: Biblioteca de Cultura de Colombia. FB-5039.

Preuss, Konrad Theodor. (1931). Arte monumental prehistórico. Excavaciones hechas en el Alto Magdalena y San Agustín (Colombia). Bogotá: Escuelas Salesianas. FB-4650; FB-4651.

\section{DOCUMENTOS DE JORGE OTEIZA EN FMJO}

(1935). FD-7343; FD-7840.

(1946a). FD-11050.

(1946b). FD-11057.

(1946c). FD-11385; FD-12074; FD-16994; FD-18751.

(1946d). FD-23007.

(1947). FD-3189.

(1948). FD-10988.

(1981). FD-10671.

(s.f.-a). FD-6505.

(s.f.-b). FD-7864.

(s.f.-c). FD-8084.

\section{HEMEROTECA DE JORGE OTEIZA EN FMJO}

Trillas, Gabriel. (1946). "Cante jondo". Revista de América, n 19. Bogotá: abril. pp. 225-239. FH-3331. 
Revista Herencia, Vol. 31 (1), enero-junio, 2018. 